\title{
G007 PATHWAY OF FORMATION AND CATALASE ACTIVITY IN A DIOXO BRIDGED MN(IV) DIMER.
}

E. L. Larson V. L. Pecoraro*, Department of Chemistry, University of Michigan, Ann Arbor, MI 48109-1055, U.S.A.

The structure of the manganese center in the oxygen evolving complex which is responsible for oxidation of water to dioxygen has not yet been elucidated. However, it is well established that at least some of the $\mathrm{Mn}$ ions are separated by $2.7 \AA$ distances. The same is true for at least one form of dinuclear manganese catalases. The most common structural motif in $\mathrm{Mn}$ model compounds that achieves this short separation is an edge-shared $\left[\mathrm{MnO}_{2}\right.$ unit [1]. However, reactivity relevant to the OEC or catalases has not previously been demonstrated for complexes of this type. Therefore the pathways of formation, decomposition and the reactivity of bis- $\mu$-oxo structures are of interest.

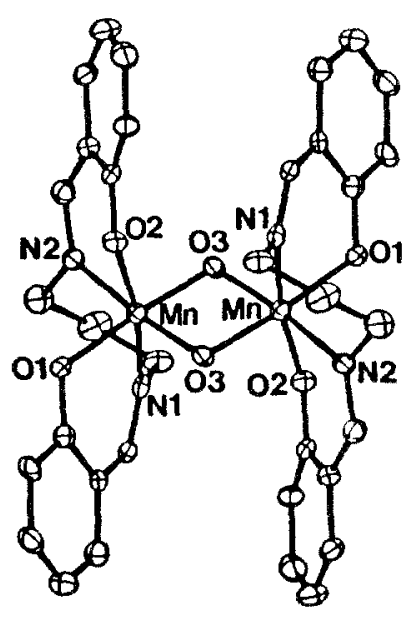

Figure 1. [Mn(SALPN)O $]_{2}$ We have examined the formation of [Mn(IV) $(\mathrm{SAPLN})(\mathrm{O})]_{2}, 1$ FIGURE 1, using peroxidic oxidants and well defined Mn(III) precursors. Hydrogen peroxide reacts with $\mathrm{Mn}$ (III)(SALPN)(ACAC),

$[\mathrm{Mn}(\mathrm{III})(\mathrm{SALPN})(\mathrm{OMe})]_{2}$ or $\mathrm{Mn}$ (III) 2 (SALPN) 3 to give 1 in quantitative yields with direct incorporation of both peroxidic

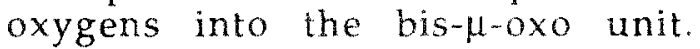
Isotopic labeling studies show that $t$ ButylOOH also reacts but follows a different pathway. The hydrogen peroxide reaction is suggested to proceed via a $[\mathrm{Mn}(\mathrm{III})(\mathrm{SALPN})]_{2}\left(\mathrm{O}_{2}-\right.$ 2)] dimer while a $\mathrm{Mn}(\mathrm{V}) \mathrm{O}$ is implicated in the $\mathrm{ROOH}$ oxidation [2].

Efficient catalase activity was demonstrated for 1 in contrast to other bis- $\mu$-oxo dimers. Isotopic labeling studies show bridge exchange which incorporates both oxygens from one hydrogen peroxide molecule into the catalyst and oxygen formation without $\mathrm{O}-\mathrm{O}$ bond cleavage. Reversible protonation studies presented suggest increased basicity in the oxide bridges of 1 compared to other bis- $\mu$-oxo dimers [3].

1. G. Christou, J. B. Vincent, L. Que,, Jr., (Ed.) In Metal Clusters in Proteins, Ch. 12, 239, A. C. S. (1988).

2. E. J. Larson, V. L. Pecoraro, J. Am. Chem. Soc. (1991) in press. 3. H. H. Thorp, J.E. Sarneski, G.W. Brudwig, R.H. Crabtree, J. Am. Chem. Soc., 111, 9249 (1989), 